\title{
Club Penguin de Disney: los nuevos modos de construcción social de la infancia*
}

Sergio Alvarado Vivas**

Recibido: 29 de abril de 2014 - Aprobado: 16 de octubre de 2014

Producto de cierta ambigüedad histórica respecto del lugar de los niños en la sociedad, en el siglo XX se edificó una noción de infancia asociada a la promoción de espacios seguros para su desarrollo personal, social y educativo. En ese contexto, surge el emporio mediático Disney, el cual apunta en el nuevo milenio a nuevos horizontes: las MMO (Massively Multiplayer Online) para niños. Prueba de ello ha sido la adquisición, por parte de dicha compañía, del Club Penguin, una plataforma que posee más de 12 millones de usuarios registrados. En el presente trabajo, se analiza la construcción de realidad que hacen los niños en Club Penguin, así como sus formas de interactuar y comunicarse en un mundo virtual mediado por el consumo, el control y múltiples concepciones de territorio. De igual forma, el estudio aborda cómo los padres de familia entienden el ciberespacio y por qué Disney se configura como un sinónimo de confianza o de protección para sus hijos. El análisis del Club Penguin se hace desde una postura crítica, con el objetivo de evidenciar el grado de penetración del discurso Disney en edades tempranas, el cual se enmascara en una MMO que pese a ofrecer altos grados de seguridad ante peligros como el ciberacoso, también transmite componentes ideológicos que pueden llegar a ser nocivos.

Palabras clave: infancia, Disney, MMO, Club Penguin, construcción de realidad.

* Artículo que presenta resultados parciales de una investigación. El presente escrito se adscribe al proyecto de tesis doctoral que actualmente desarrollo y se denomina "Club Penguin de Disney: Los nuevos modos de construcción social de la infancia a través de plataformas masivas multijugador en línea", inscrito en la Facultad de Ciencias de la Comunicación de la Universidad Rey Juan Carlos de España.

** Docente en la Corporación Universitaria Minuto de Dios y de la Maestría en Comunicación, Desarrollo y Cambio Social de la Universidad Santo Tomás. Orienta las cátedras de Investigación en Comunicación, Lenguajes Globales y Comunicación en Medios Digitales. Doctor en Comunicación y Ciencias Sociales, por la Universidad Rey Juan Carlos de Madrid, España. Máster en Comunicación y problemas socioculturales de la misma Universidad. Comunicador Social egresado de la Universidad Santo Tomás (Bogotá). Dirección postal: Cra. 74 \# 81 C-05, Bogotá, Colombia. Correo electrónico: sergioalvarado@usantotomas.edu.co 


\section{Disney Club Penguin: new modes of social construction of childhood*}

Sergio Alvarado Vivas*

A bstract

Product of certain historical ambiguity about the place of children in society, in the twentieth century a notion of childhood associated with promoting safe spaces for their personal, social and educational development was built. In this context. The media emporium Disney arises which aims in the new millennium to new horizons. The MMO (Massively Multiplayer Online) for children:. Proof of this was the acquisition by that company, of Club Penguin, a platform that has over 12 million registered users. In this paper, the construction of reality that children do in Club Penguin is analyzed, and their ways of interacting and communicating in a virtual world mediated by consumption, control and multiple conceptions of territory. Similarly, the study addresses how parents understand cyberspace and why Disney is configured as a synonym of trust or protection for their children. The Club Penguin analysis is done from a critical stance in order to demonstrate the degree of penetration of the Disney speech in an early age, which is masked in a MMO that despite offering a high degree of security against dangers such as cyberbullying, also broadcasts ideological components that can become harmful.

Keywords: Children, Disney, MMO, Penguin Club, construction of reality.

Article which submits partial results of a research project. This paper is part of a $\mathrm{PhD}$ thesis currenlty under development and called "Disney's Penguin Club: New ways of social construction in childhood through MMOs" registered at the Faculty of Communication Sciences at Universidad Rey Juan Carlos de España.

** Professor at the University Corporation Minuto de Dios and the Master of Communication, Development and Social Change at the University Santo Tomas. Orienta Research Chairs in Communication, Global Languages and Communication in Digital Media. PhD in Communication and Social Sciences, Rey Juan Carlos in Madrid, Spain University. Master in Communication and socio-cultural problems at the same university. Social Communicator graduated from the University of Santo Tomas (Bogotá). Address: Cra. 74, 81 C-05, Bogotá, Colombia. Email: sergioalvarado@usantotomas.edu.co. 


\section{Club Penguin de Disney : les nouvelles manières de construction sociale de l'enfance*}

Sergio Alvarado Vivas**

\section{Résumé}

Produit de certaine ambiguité historique en relation au lieu des enfants dans la société, dans les XXe siècle s'est édifié une notion d'enfance associée à la promotion d'espaces sûrs pour son développement personnel, social et éducatif. Dans ce contexte, il surgit, le grand emporium médiatique Disney qui met en joue dans le nouveau millénaire à de nouveaux horizons : les MMO (Massively Multiplayer En ligne) pour des enfants. Une preuve de cela a été l'acquisition, de la part de la dite compagnie, de Club Penguin, une plate-forme qui possède plus de 12 millions d'utilisateurs inscrits. Dans ce travail, on analyse la construction de la réalité que les enfants font dans le Club Penguin, ainsi que ses formes d'interagir et de communiquer dans un monde virtuel à moitié plein, médié par la consommation, le contrôle et les multiples conceptions de territoire. De la même manière, l'étude aborde comment les parents de famille entendent le cyberespace et pour quoi Disney se configuré comme le synonyme de confiance ou de protection pour ses enfants. L'analyse de Club Penguin est faite à partir d' une attitude critique avec l'objectif de mettre en évidence le degré de pénétration du discours Disney dans les âges précoces, lequel se masque dans une MMO qui malgré offrir de grands degrés de sécurité en face des dangers comme le cyberharcèlement, il transmet aussi les composants idéologiques qui peuvent arriver à être nocifs.

Mots clés: L'enfance, Disney, MMO, Club Penguin, la construction de réalité.

* Article montrant les résultats partiels d'une recherche. Le texte est rattaché au projet de thèse de doctorat en cours, intitulée «Club Penguin de Disney: les nouveaux modes de construction sociale de l'enfance par le biais des platesformes massives multijoueur en ligne» inscrite dans la Faculté des Sciences de la Communication de l'Université Rey Juan Carlos (Fuenlabrada, Espagne).

** Enseignant dans la Corporation Universitaire Minute de Dios et de la Maîtrise dans la Communication, le développement et Cambio Social de l'Université Santo TomasTomas. II oriente les cours de recherche à la Communication, les Langages Globaux et la Communication des médias digitaux.PhD dans la Communication et les Sciences Sociales, par l'Université Roi Juan Carlos de Madrid, Espagne. Master en Communication et les problèmes socioculturels de la même université.Communicateur Social diplômé de l'Université Santo Tomas de aquino (Bogotá). Adresse: Cra. 74 \# 81 C-05, Bogotá, Colombia. Email: sergioalvarado@usantotomas.edu.co. 


\section{Introducción}

Internet ha proporcionado nuevos modos de comunicarse, lo que ha propiciado el surgimiento de redes sociales de todo tipo, donde usuarios del mundo entero interactúan entre sí intercambiando información y estableciendo lazos de comunicación multimediales. Sin embargo, la exposición de datos e información a través de Internet supone un peligro latente para cualquier tipo de usuario. A consecuencia de ello, colectivos como el infantil pueden encontrarse amenazados por ciberacosos o suplantaciones de identidad con fines diversos, pero negativos en todos los casos.

Por consiguiente, la preocupación generalizada en la sociedad por la vulnerabilidad de los niños, impulsó el surgimiento de aplicaciones dedicadas exclusivamente para ello, entre ellas nacieron plataformas masivas multijugador online (MMO) para niños, donde una de sus pioneras es Club Penguin, una plataforma desarrollada por informáticos canadienses, la cual sería comprada años más tarde por el emporio Disney, y que en la actualidad marca la pauta en el campo de las MMO infantiles como alternativas y espacios que ofrecen seguridad y modos de control por parte de los padres.

Así pues, el presente artículo expone los resultados de una investigación encaminada a comprobar la hipótesis de que las plataformas MMO (Massively Multiplayer Online) dirigidas a niños, tales como Club Disney, propician nuevos modos de construcción social de la realidad, al trasladar a un territorio seguro del ciberespacio, diversas dinámicas y espacios del mundo real, tales como la adquisición de bienes y servicios, la interacción con otros sujetos con fines diversos, el desenvolvimiento en lugares privados y públicos. Sin embargo, esto supone la inducción al público infantil, a su vez, a dinámicas consumistas y materialistas desde edades tempranas, deformando en parte la idea inicial de territorio seguro y ausente de peligros.

\section{La infancia a través de la historia}

Si nos remontamos a la antigüedad, podemos observar que en grandes imperios como el egipcio (2500 a. C.), los conocimientos sobre la infancia eran muy ignotos, por lo que se daban una serie de contradicciones. Por una parte los niños cumplían importantes papeles en ritos y actividades religiosas, pero a su vez, se daban situaciones contrarias donde las madres egipcias creían todo un honor el sacrificar a sus hijos a los cocodrilos del Nilo, ya que esto significaba tener contenta a esa deidad, caso que se solía replicar con otras de los innumerables dioses que por ese entonces tenían.

En materia de literatura, las historias que se referían a niños tocaban temas como el abandono, aquellos relatos narraban las penurias y desventuras de chicos que abandonados en bosques o lugares alejados de sus hogares, se debían 
enfrentar a toda una serie de situaciones dramáticas y llenas de dificultades, aquellos infantes serían reseñados a lo largo de la historia como "expósitos" (Buenaventura, 1998).

Esta constante relacionada al abandono en mitologías como la romana también estaban presentes; no hace falta irse muy lejos para poner en evidencia relatos como el de los niños gemelos Rómulo y Remo, los legendarios fundadores que sobrevivieron gracias a que fueron amamantados por una loba, pues fueron abandonados por su madre para evitar que su esposo, el rey Amulio, se enterase de su infidelidad. Por su parte, cosmogonías como la griega tocaban los temas de abandono de niños de forma recurrente, donde los errores y dejaciones de los humanos eran justificados por sus dioses, así que si sus grandes deidades devoraban niños (tal como lo hizo Neptuno con sus hijos, a excepción de Zeus) para conservar su trono, porque no ha de justificarse el abandonar en frondosos bosques a los niños que en algún momento dado podían representar una carga.

Seguida al esplendor de la época romana llegaría la Edad Media, donde en general los intentos de representar la infancia eran muy escasos, no por dificultades o faltas de capacidad, sino por el simple hecho de que los niños no tenían un espacio claro en el arte ni en las diferentes formas de representación de aquella época. Phillippe Ariès (1962) da cuenta de ello, al poner como ejemplo pinturas donde los protagonistas son evidentemente los niños; escenas provenientes de los evangelios como la de Jesús pidiendo que los niños se acerquen a él, son representadas en aquellos años como hombres pequeños, de menor talla que Jesucristo pero sin ningún rasgo visible de niño.

Luego de varios siglos, con la llegada del renacimiento (siglo XIV) se continuará con la evolución de las representaciones de los niños, Ariès (1962) destaca en especial la figura religiosa de la Virgen María y el niño Jesús, la cual comenzó a trascender como una escena real, propia de una situación cotidiana y que se replicaría en otras figuras religiosas tales como la infancia de Juan Evangelista, donde las nociones maternidad e infancia se harían más y más sólidas. No obstante, esta reiterada representación de impúberes estrechamente relacionados con lo divino y religioso empezaría a trascender en el terreno laico en los siglos XV y XVI (Ariès, 1962).

Con la venida de la Ilustración o Siglo de las Luces (siglo XVIII) inicia lo que en palabras de Ariès (1962) sería el descubrimiento de la infancia. Por una parte, se empiezan a emplear sobrenombres y maneras diferentes para referirse a los niños, llámese chiquillo, nene o chaval (por poner ejemplos en nuestro idioma español), lo que en los ámbitos privados (familiares) comenzaron a ser muy usados, promovidos por las nodrizas quienes eran las que tenían bajo su cuidado la mayor parte del tiempo a los infantes.

Sin embargo, sería hasta la edad contemporánea (siglo XIX) cuando la literatura caló en buena parte de los sectores de la sociedad, y aprovechándose de la invención de la imprenta varios siglos atrás, más exactamente en 1450, comenzaría un 
progresivo incremento en la difusión de escritos de toda clase. Dicha situación con el pasar de los siglos llevaría a despertar el interés por parte de diversos autores europeos por recolectar y consignar de manera escrita muchos de los relatos populares, que llevarían a la niñez a verse cada vez más participes de este tipo de historias.

De esta manera se comienzan a mover unas fuertes corrientes por el territorio europeo, empeñadas en recuperar y preservar el "Folklore" (término acuñado por William John Thoms en 1846 que se refiere al saber popular) que comenzarían a dar sus frutos en el campo de la literatura para niños gracias al francés Perrault y a los hermanos Grimm, quienes serían los primeros en publicar libros de cuentos y relatos populares, que curiosamente pese a no ser en principio dirigidos a lectores infantiles, serían los que responderían de mejor manera a aquellas historias inmersas en fantasías y aventuras (Jiménez, García y Maroto, 1999).

Asimismo, Buenaventura (1998) nos expone cómo este fenómeno se replica en diferentes latitudes; uno de los más referentes y conocidos por todos son las novelas de Charles Dickens, que arroja datos sobre la vida infantil por aquellos años, en medio de metáforas y relatos autobiográficos. Obras como "Oliver Twist" y “David Copperfield" tendrían una gran acogida en Inglaterra, a razón de ser las primeras novelas que ponían como protagonista a un niño en medio de las condiciones sociales más precarias que se podían encontrar por ese entonces en la isla británica.

Ya en el siglo XX, a razón de los grandes acontecimientos bélicos de la primera mitad del siglo XX, el niño empezó a ser visto como una mano de obra barata y un nicho a explotar con fines particulares, donde a razón de las dos guerras mundiales la niñez fue un foco de explotación en diversas áreas, especialmente en los bandos soviéticos y alemanes como manera de suplir la ausencia de infantería suficiente para las confrontaciones territoriales.

Sin embargo, con el fin de la guerra se comenzaría a dar cabida a la protección de la infancia con la declaración de los Derechos del Niño en 1959, donde en una carta magna se consignó una serie de lineamientos a cumplir en el mundo entero más allá de la raza, etnia, nacionalidad, religión o estatus económico. En aquella carta se destacaron derechos tales como el derecho a una nacionalidad, a un nombre, a seguridad social, a recibir afecto y amparo, a recibir educación, a no ser abandonados, entre otros.

La posguerra a su vez dio pie a un fenómeno crucial, que quisiera destacar particularmente: el "baby boom", suscitado particularmente en Estados Unidos e Inglaterra, quienes entre 1946 y 1960 mostraron una notable explosión de natalidad luego de la vuelta a la vida civil de muchos de los combatientes que estuvieron en la prolongada confrontación bélica. Esta situación sería aprovechada por un emporio muy conocido por todos: Disney. 


\section{El discurso Disney}

Como es bien sabido, la industria creada por Walter Disney es sinónimo casi obligado de inocencia infantil, eso en cuanto al pensamiento popular claro está, donde la constante asociación con símbolos de seguridad y felicidad que resguardan a los niños con el pasar de los años se vuelven más fuertes y sólidos (Giroux, 2001). Así pues, resulta valioso recorrer algunos de los aspectos más sobresalientes que se refieren a Disney y su manera de insertarse en la cultura popular de la gente, para comprender su amalgama inevitable que combina familia, infancia y consumo.

Walt Disney consciente de la situación de la sociedad donde se desenvolvía, adquirió como uno de sus estandartes a la inocencia como su forma de expresar una serie de relatos que se soportaron en esa asociación de niñez, inocencia y entretenimiento. Como bien lo expresa Giroux (2001), quien nos expone que la concepción "disneysiana" nació de la elaboración de un lenguaje donde los niños y los mayores encontraran placer y diversión sumado a un conjunto de elementos identitarios.

De esta manera los relatos portadores de la "inocencia Disney" se incluyeron poco a poco dentro de cada uno de los hogares, mezclándose no solo con una serie de elementos propios de la cultura popular, sino además fomentando un ambiente propicio para el consumismo de los productos, al otorgar un determinado status dentro de los cánones populares, como contenidos "adecuados" y desprovistos de elementos negativos para el niño y su familia.

Y es que el encanto Disney se construyó a partir de un discurso que se basaba en el lado alegre de la vida, donde tomando ejemplos descritos por Dorfman y Mattelart (1973), podemos evidenciar caracterizaciones en las cuales hasta el más avaro de los personajes, Rico McPato, un tacaño millonario, muestra en determinados momentos rasgos de humanidad con sus sobrinos, en medio de las diferentes aventuras que atraviesan con el fin de conservar intacta su fortuna. Así pues, se trata de un constante juego entre la fantasía y lo real, donde existen semejanzas con la realidad pero a su vez expresa ideales y aspiraciones de patrones de conducta.

Pero Walter Elías Disney consideraba un elemento adicional además de la familia, infancia y consumo: la educación. Ya que a su juicio él consideraba que la escuela no podía ser el único canal educativo, para Disney era clave la cultura popular como productora de conocimiento y como entorno próximo a sus audiencias, y en consecuencia para Walter Disney el entretenimiento y la diversión eran la clave para articular educación y cultura popular.

Esta postura descrita, llevó a que Disney efectuara una inevitable formación de una frontera muy difusa entre educación y entretenimiento, que le permitió insertar y justificar las figuras comerciales tales como Disneylandia, eso sin contar todo el llamado "merchandising" que se fundió con la cotidianidad y el 
devenir de cada una de las familias que de una u otra forma le fueron abriendo sus puertas al universo Disney. Y es que cuando nos referimos a los elementos familia, infancia y su apertura a lo que Giroux (2001) denomina esfera de consumo, es inevitable recurrir a Dorfman y a Mattelart (1973), quienes identifican en los personajes y relatos de Disney todo un cúmulo cultural que se ha insertado en cada hogar. Situación que retribuye la industria Disney al hacerlos participes de una gran familia: el hogar Disney.

Más allá de la cotización bursátil, sus creaciones y símbolos se han transformado en una reserva incuestionable del acervo cultural del hombre contemporáneo: los personajes han sido incorporados a cada hogar, se cuelgan en cada pared, se abrazan en los plásticos y las almohadas, y a su vez ellos han retribuido invitando a los seres humanos a pertenecer a la gran familia universal Disney, más allá de las fronteras y las ideologías, más acá de los odios y las diferencias y los dialectos (Dorfman y Mattelart, 1973, p. 8).

Así que todo este panorama nos lleva a ver de primera mano la fuerza y el impacto de la industria cultural promovida por Disney, que ha sido capaz de influir en gran parte de las facetas de nuestras vidas. Pero aun algo más importante se da, y es cómo el niño establece una relación con inocencia, ciudadanía y consumo, lo que en palabras de Giroux (2001) se traduce en el cómo la infancia enlaza valores cívicos y valores mercantiles. De allí surge la preocupación generalizada por parte de los críticos hacia el fenómeno Disney, la cual se fundamenta en el temor a la voraz cultura corporativa de conglomerados que generan gran atracción en el público infantil, y que apuntan hacia incentivar el gasto de capital por parte de los niños y las familias, que juegan con el peligroso postulado social que se insinúa en términos generales, donde la juventud que no consume sencillamente no cuenta por ser eminentemente potenciales sujetos problemáticos.

Así pues, la dinámica de Disney radica en sus incansables intentos porque su mundo sea aceptado como natural, y que enmascarado en el mundo animal representado en sus animaciones y relatos, les permite jugar con lo real y lo fantasioso, pero no precisamente con ánimos pedagógicos, ya que coincidiendo con Dorfman y Mattelart (1973), el recurso de los animales es realmente para envolver a los niños en un mundo que en principio les ofrece libertad de creación y desenvolvimiento, al encontrarse con personajes igual de "inocentes" y cariñosos con los cuales no corren ningún peligro, por el contrario, pueden sentirse con la tranquilidad y el libre albedrío de jugar, interactuar y mezclarse.

Se trata de un juego donde Disney usa cuerpos y ambientes si se quiere impostores o sustitutos, donde pone a personajes que bien podrían equipararse con un individuo de la vida real en cuerpos de animales domésticos y silvestres de todo tipo: por un lado podemos ver al "Pato Donald", un haragán que vive a costa de su familia; "Tribilín", un perro que representa el hombre común clase media que vive con sus errores y torpezas, pero que es feliz con su estilo de vida, y bueno, para no ir muy lejos se encuentra el emblemático "Mickey Mouse", que en sus polifacéticas caracterizaciones en algún momento ha representado diversos fragmentos de la sociedad (Dorfman y Mattelart, 1973). 
Lo que es cierto, es que el constante uso de la inocencia por parte de Disney permite que a simple vista se muestren como benevolentes e incansables en reivindicar a la infancia, pero a su vez la mercantiliza enmascarándola con la fantasía y metáforas que suscitan sentimentalismos, uno de los mejores ejemplos son los famosos parques temáticos que apuntan a "una exaltación sin contradicciones del pueblo americano y de su historia" (Watts, en Giroux, 2001), lo que impide una directa identificación de la compañía con el mundo de los negocios, ubicándose con mayor facilidad, reitero, en cada hogar y familia no solo de América del Norte sino en diversas latitudes del mundo entero.

\section{El fenómeno Club Penguin}

Para hablar de plataformas como Club Penguin, es necesario hablar de los juegos multijugador en línea (denominados $\mathrm{MMO}$ ), los cuales parten de la idea básica de un videojuego de consola convencional, con el plus de que este se juega a través de Internet, lo que permite la participación de un sinnúmero de jugadores en lo que se denomina un mundo virtual.

Así pues, este tipo de plataformas se desenvuelven bajo una serie de características que las definen y distinguen de, por ejemplo, las redes sociales u otro tipo de comunidades virtuales disponibles en la red.

El surgimiento de estas plataformas tiene como orígenes la idea clásica de los juegos de tablero, tales como "Calabozos y Dragones", sin embargo, su traslado al mundo tecnológico iniciaría a mediados de los años 80, uno de los primeros productos fue "Islands of Kesmai", su impacto en principio fue bastante limitado, dadas las condiciones que Internet tenía por esa época (Steinkuehler, 2005). Sin embargo, con las mejoras de accesibilidad de Internet a finales de los 90, se dio un rápido crecimiento de las $\mathrm{MMO}$, de donde surgieron títulos de referencia como "Second Life" y "World WarCraft" (desarrollado por Microsoft), el cual en la actualidad es el de mayor usuarios suscritos en todo el mundo (Belli y López, 2008).

Los MMO se destacan por ser juegos sostenidos y ambientados en universos y personajes ficticios, es decir, antes que nada un MMO tiene una temática, la cual es la que le da sentido y coherencia al mundo virtual. Sumado a ello, estas plataformas ofrecen la posibilidad de crear un avatar, los cuales han de evolucionar en la medida del desempeño del jugador, llámese cúmulo de experiencia, adquisición de determinados elementos, herramientas, objetos, etc. Por ende, esto permite no solo el crecimiento del personaje del usuario, sino además adquirir un status o nivel dentro de ese mundo virtual.

Como un fenómeno más neófito se ubican las MMO para niños, este tipo de plataformas que se dirigen a un público de menores de 14 años, han tenido un acelerado crecimiento en los últimos años. Como punto de partida podemos 
ubicar a Club Penguin, una MMO para niños que fue desarrollada por un grupo de informáticos canadienses en el 2005, y se convirtió en una de las pioneras en cuanto a público de infantes (Barnes, 2007).

A diferencia de los $\mathrm{MMO}$ convencionales, estos proveen un plus de mayores restricciones a la hora de comunicarse y relacionarse con otros usuarios, esto con el fin de proteger a los usuarios menores de edad de posibles ciberacosos o uso indebido de sus datos personales. Así pues, estas plataformas, ambientadas en diagramaciones claramente dedicadas a niños, se esmeran en la protección y en vender esos mundos virtuales como territorios seguros donde los padres o tutores han de tener mucha más tranquilidad a la hora de dejar a sus niños navegando por la red (Nathan, Meyers y Unsworth, 2009).

Hablamos de un fenómeno que apenas nació en el 2005, y que por ende ofrece aún muchas incógnitas sobre la incidencia real en los usuarios infantiles. Lo que es cierto es que su crecimiento ha sido acelerado, lo que al día de hoy permite tener una oferta considerable de plataformas variadas, gratuitas o por cobro que se dedican a captar público infantil, tal es el caso del ya mencionado Club Penguin, Boom Bang, Webkinz, ToonTown, Moshimonsters, entre otros.

A tal punto llegó el éxito del Club Penguin que dos años después de estar en funcionamiento, el emporio Walt Disney compraría todos los derechos sobre el "website", al percatarse del importante nicho que se estaba gestando en este juego masivo en línea (Barnes, 2007). Su creación radicó a partir de la necesidad de un grupo de canadienses de ofrecerles a sus hijos la posibilidad de navegar en la red sin contratiempos y con las mayores garantías de seguridad posibles.

Al tener en la actualidad más de 4 millones de usuarios, en principio parece ser la plataforma de mayor calado, al estar soportada por Disney, lo que le permite ofrecer mayores calidades en cuanto a control, empleo de moderadores 24 horas y diversidad en sus opciones de navegación.

Pero, ¿de qué trata esta plataforma en concreto?, en principio Club Penguin se muestra como un mundo virtual cubierto de "nieve" en el que los niños juegan e interactúan con amigos a través de pingüinos que usan como avatar. Su funcionamiento es similar a otros $\mathrm{MMO}$, donde los jugadores crean su avatar (en este caso un pingüino) y luego recorren la isla del Club Penguin, donde pueden realizar diferentes actividades como chatear, enviar postales, usar emoticones $\mathrm{o}$ bien realizar acciones predeterminadas tales como saludar o bailar. Además de esto, los usuarios también asisten a fiestas y otros eventos especiales; pueden actuar en obras de teatro, adoptar mascotas y cuidar de ellos (Nathan, Meyers y Unsworth, 2009).

Como aspectos adicionales, cabe agregar que los usuarios no solo participan de juegos, sino que también esto les permite ganar "monedas" virtuales que pueden utilizar para diseñar sus propios iglús (espacio o profile) y comprarse miles de conjuntos de ropa para sus pingüinos (upgrade de sus avatar). 
En materia de seguridad como parte de su compromiso con la creación de un ambiente online seguro para los niños, Club Penguin dispone de dos opciones de chat: uno de alta seguridad con saludos y acciones predeterminadas, o uno estándar.

El público al cual se dirige concretamente es a niños de 6 a 14 años, sin embargo, está abierto a usuarios de todas las edades. A razón de ello, ofrece filtros de seguridad que permiten proteger a los niños de posibles acosadores o de personas que quieran hacerse con sus datos personales. A diferencia de otras plataformas, esta tiene no solo software que oficia como filtros, sino además emplea a personas que ofician como moderadores 24 horas, lo que garantiza mayor protección para los usuarios (evitar grooming o ciberacoso).

La plataforma permite controlar y monitorear el tiempo que dedican los niños en Club Penguin, todo esto gracias a funciones que limitan el tiempo total de juego del infante, según lo crea conveniente el padre o tutor, y como valor añadido no contiene publicidad de terceros (a diferencia de otros MMO que sí la tienen a razón de sostenibilidad), lo que evita en gran medida posibilidades latentes en las cuales el infante pueda salirse de la interfaz de la plataforma y navegue por páginas de otro tipo.

\section{Metodología}

Respondiendo a los objetivos planteados en esta investigación, se consideró un enfoque eminentemente cualitativo para aproximarse de manera más certera y cercana al objeto de estudio. Una metodología de este tipo implica hablar de lo fenomenológico como el punto de partida para la recogida de datos, en esta perspectiva podemos hallar a Deutscher (1973) y a los estudios sociológicos de Berger y Luckmann (1966), como los referentes clave a la hora de hablar de comprender la realidad desde la experiencia del actor.

En consecuencia, al hablar de las plataformas multijugadores en línea para niños como un fenómeno con pocos años de existencia, se consideró una mirada desde la cualidad porque para esta metodología ninguna porción de lo social es trivial como para dejarse a un lado y no ser objeto de ser estudiado de forma científica. Sumado a esto, Taylor y Bogdan (1987) refuerzan la importancia de los estudios de estas características debido a que esta perspectiva enfoca fuertemente sus esfuerzos en una validez interna del conocimiento hallado, y gracias a su enfoque humanista fue mucho más fructífero abordar un objeto de investigación donde uno de los protagonistas es la infancia, quienes como se ha visto a lo largo de la historia, no han tenido demasiada voz en los procesos sociales en lo que se han vistos inmiscuidos.

Es aquí donde fue decisivo tener como referencia para el marco metodológico lo que se ha hecho desde las ciencias sociales en relación a la infancia. Sin lugar 
a dudas, uno de los ejes que permiten entender con mayor facilidad el éxito de Disney como industria son los estudios de Mattelart (1973), quien no desdeñó los productos que a lo largo del siglo XX se han venido reproduciendo en buena parte del mundo, por el contrario, estableció que existen discursos enmascarados en relatos inocentes a primera vista.

No obstante, la capacidad persuasora de Disney ha radicado en su habilidad indiscutible de leer los contextos para así insertar a través de sus productos, valores, cualidades y sensaciones de seguridad y bienestar. Desde la psicología y la educación se pueden hallar los referentes más fuertes respecto a la infancia y su desarrollo, solo hace falta referenciar a Freud (1921), quien desde su perspectiva del psicoanálisis concibió a la infancia como etapa clave para el desarrollo óptimo de un individuo.

En ese orden de ideas, vale la pena reseñar a María Montessori (1936) como una de las pioneras en lo que se refiere a comprender a la infancia como un proceso donde el niño es propenso a absorber con gran facilidad todo tipo de experiencias, por lo cual, es imperante que el adulto garantice un ambiente propicio rodeado de seguridad y ambientes afectivos positivos.

Enmarcados en este panorama, es donde han hecho su aparición los medios masivos como un replicador de los peligros latentes para los niños, donde lo que denomina Theodor Adorno y Edgar Morín (1967) como industrias culturales han sacado ventaja para posicionar sus productos como la vía factible de mitigar los temores que como padres de familia pudiesen tener ante un entorno potencialmente hostil hacia sus hijos, peligros que el mismo Phillip Aries (1962) confirma que han sido una constante a lo largo de la historia más allá de los esfuerzos realizados.

Por consiguiente, teniendo siempre presente esa búsqueda del conocimiento directo de la vida social que resalta Blumer (1969) en relación al investigar de manera cualitativa, se contempló, en primera instancia, realizar una descripción a profundidad de la plataforma Club Penguin, con el fin de identificar con claridad los elementos que componen a la misma, además de establecer los tipos de interacción que ofrece, que sumado a las herramientas y aplicaciones a las que recurre esta plataforma $\mathrm{MMO}$, permitió abordar con mayor conocimiento y propiedad las características del mundo virtual donde se desenvuelven los usuarios.

Así pues, se examinó en principio el index (página inicial del sitio web), y luego se exploró cada una de las rutas de navegación, observando sus contenidos y publicaciones, además de capturar algunos "screenshots" del sitio web, con el fin de ilustrar de mejor manera las características del Club Penguin y el abanico de información del que dispone previo a la entrada en sí al Multiplayer Massively Online.

Posteriormente, luego de inspeccionar la información del sitio web, se procedió a realizar un proceso similar dentro de la $\mathrm{MMO}$, es decir, que le dimos clic al 
botón jugar y nos adentramos realizando un login como un usuario más para recopilar información general de la estructura del mundo virtual. Este procedimiento implicó una preparación previa, tales como un diario de campo y parámetros de navegación.

Seguido a esto, se realizaron conversatorios y talleres con niños entre 8 y 12 años, que por una u otra circunstancia han tenido algún contacto con el Club Penguin y plataformas online similares, para recoger de primera mano, las impresiones de los usuarios activos y potenciales de las MMO para niños.

Dado que el diseño del Club Penguin plantea que los tutores o padres de familia son parte fundamental para la sinergia de la plataforma, se realizaron grupos de discusión con ellos para conocer qué tanto conocían sobre la plataforma, su postura frente a Disney y sus apreciaciones frente a Internet como un espacio de frecuente visita por parte de sus hijos. De igual forma, se estableció la entrevista a profundidad como instrumento de recolección de información; si bien existen diversos tipos de entrevista a profundidad, se consideró como la más adecuada la que exponen Taylor y Bogdan (1987), quienes plantean un tipo de entrevista que se dirige al aprendizaje sobre hechos y acciones que no se pueden observar directamente, "más que cualquier otro enfoque de la ciencia social, nos permite conocer íntimamente a las personas, ver el mundo a través de sus ojos, e introducirnos directamente en sus experiencias" (Shaw, 1931, p. 198 en Taylor y Bogdan, 1987).

En consecuencia, lo que a continuación se plasma y describe es el producto de la aproximación a detalle al website y a la MMO del Club Penguin, inmersión que tuvo como fin recoger información valiosa para comprender con mayor certeza sobre qué terreno nos movemos a la hora de navegar por una MMO para niños. La cual fue guiada por un manual de navegación que se ciñó a las políticas de seguridad de la plataforma para no vulnerar a posteriori a otros usuarios y poder recoger datos más certeros.

\section{Conclusiones}

Como resultado del proceso de investigación, se lograron construir varios aspectos concluyentes, los cuales permitieron establecer perspectivas y horizontes de cara a continuar indagando en relación a cómo los usuarios, en este caso los niños, construyen realidad y despliegan todo un acervo de prácticas culturales en un entorno digital como una MMO.

Así pues, los resultados arrojados dan certeza que la plataforma multijugador en línea para niños Club Penguin se posiciona en la actualidad como uno de los territorios seguros más populares para la infancia. Sus estándares de seguridad basados en 2 sistemas: por un lado una programación predeterminada que filtra las conversaciones entre usuarios, y por el otro la presencia 24 horas 
de moderadores de carne y hueso, evidencian un esfuerzo por darle valía a la navegación en un entorno digital seguro. Sumándose a esto, la posibilidad de ejercer un control parental potencia los modos de monitorear a los niños, y lo que es mejor, pone como reto adicional reducir la brecha digital de los tutores de los infantes para consolidar los modos y las formas para hacer de las MMO como Club Penguin espacios aún más seguros.

Bajo este marco de seguridad, nos encontramos con una MMO que se basa en tres dinámicas: explorar, conocer y evolucionar, las cuales articulan a los avatar que se desplazan a lo largo y ancho de la plataforma. El niño en consecuencia se encuentra en un mundo virtual que no se limita a ofrecer seguridad sino que le permite vivir experiencias sustancialmente diferentes en cada ocasión, dado que es una plataforma multidimensional y que no permanece estática durante demasiado tiempo.

El mundo virtual se desenvuelve en lugares públicos, que pueden ser espacios urbanos o rurales, donde a través de minijuegos, actividades grupales de exploración y tiendas diversas, les brindan a los usuarios numerosas posibilidades para personalizar sus avatar y sus espacios propios, tales como el iglú. La MMO hace hincapié en que los usuarios hagan "upgrade" de sus pingüinos, ya que este es el incentivo más importante para ser partícipe de las diversas actividades, evolucionar y ganar prestigio en la comunidad.

Y es que aquí donde aparecen los peligros en medio de un entorno aparentemente inocente, ya que la máxima de la plataforma se sustenta en el ascenso social del usuario. El concepto de comunidad comienza a quebrantarse y avizorar algunas grietas, ya que al contrario de lo que se pensaría de una plataforma horizontal y democrática, Club Penguin empuja a sus usuarios a interactuar cada vez más con el ánimo de que cada pingüino tenga posibilidades de ascenso social, de poder adquisitivo, de poder de información y reconocimiento en un entorno digital.

El ascenso social de un usuario se mide por el monto de dinero de Club Penguin que posea, en la cantidad de objetos que tenga en el iglú (muebles, adornos, etc.), en los roles desempeñados y en los derechos de acceso a zonas privadas y exclusivas en donde no todos los usuarios pueden entrar. Pareciese como si se emularan sistemas económicos como el capitalista y lo maquillaran en una plataforma infantil, donde los niños se vuelven el cultivo de los consumidores del futuro, de quienes al igual que sus padres expresarán agrado hacia Disney y verán con buenos ojos que sus hijos sigan la misma línea.

Ante esta sólida infraestructura de mercadeo "disneysiano", el aspecto clásico de una red social queda a un lado, donde ya no hace falta subir una foto real, simplemente hace falta proyectarme a través de la figura de un avatar que responde a las características básicas de un pingüino.

Club Penguin se soporta en un discurso clásico de Disney, donde exponen la posibilidad de ascender y tener reconocimiento (publicar en el periódico del 
Club Penguin, hacer una fiesta para otros usuarios, donar dinero para fines sociales en el 1.0) donde tener poder es sinónimo de benevolencia y de tener que rendirles pleitesía, porque al parecer se lo han ganado con esfuerzos diversos. Sin embargo, por otra parte se le da a los niños un discurso donde los roles típicos de las clases populares no son malos; por ello ser un pizzero o un minero, puede ser divertido, más allá de lo mal remunerado que pueda ser en la realidad. Las afirmaciones de Mattelart realizadas décadas atrás sobre Disney encajan a la perfección en este modelo 2.0, donde un Pato Donald o un Tribilín pueden tener desventuras o trabajos duros, pero en medio de un síntoma de resignación encuentran en fugaces momentos de entretenimiento lo que Disney nos ha vendido como felicidad y alegría.

La plataforma multijugador en línea de Disney plantea una dinámica donde incluso lo que consideramos privado no tiene por qué serlo, donde el niño puede tener un iglú (casa) y sin previo aviso, ser visitado a diario por un sinnúmero de pingüinos que podrán observar y deducir qué tan alto es el nivel socio-económico de ese avatar en la medida que puede observar todo lo que ha comprado y personalizado en su espacio.

Si bien existe una brecha notable entre el usuario que paga y obtiene una membresía y quien accede al Club Penguin de manera gratuita, dado que quien no paga las mensualidades carece de posibilidades plenas de navegación, limitando su acceso a diversos contenidos del mundo virtual. En ambos casos existe la oportunidad de recoger, recolectar y ganar monedas del mundo del Club Penguin, un dinero que como en cualquier entorno, busca abrir la posibilidad de adquirir bienes y servicios. Nuevamente la premisa de consumir como método para ascenso social se presenta como algo natural y aceptado por todos.

Es aquí donde se inmiscuyen territorios peligrosos para la infancia, dado que se da una disyuntiva respecto a la fuerte incidencia que tienen estas monedas en el desarrollo de un usuario dentro de la plataforma. Por un lado, ese dinero virtual tiene la posibilidad de traducirse en accesorios, mascotas y enseres para su pingüino, mientras que por el otro se convierte en un factor de oportunidad para que los niños empleen ese dinero en campañas 1.0 que paralelamente promueve el Club Penguin en pos de ayudar a la infancia en riesgo de exclusión en diversas latitudes del mundo.

De igual forma la plataforma proclama discursos que pueden ser nocivos, el factor querer ser, diferenciarme de, ser mejor que, se vuelven los detonantes de un discurso Disney donde para ser un usuario con peso e influencia se requiere no solamente de una suscripción, sino que implica una navegación continua, una competencia con otros, que si bien pareciera inofensiva, sin dudas apunta a reafirmar el imaginario del bien adquirido y lo decisivo de poseer un estatus dentro de un contexto determinado.

Más que plantearlo como resultados apocalípticos, vale la pena aclarar que lo que arroja esta investigación evidencia el panorama Disney llevado a entornos 
digitales infantiles. Se trata de dejar sobre la mesa cómo la idea de seguridad que ha vendido Disney por casi un siglo sigue siendo vigente y replicándose de manera viral en cada uno de sus productos. Queda claro que para los padres de familia no es del todo negativo esta situación, ya que tienen claro que como cualquier otra plataforma necesita formas de subsistir, y los modos de mercadeo y recolección de capital por parte de Disney es respuesta a la dinámica de cualquier otra empresa productora de contenidos. Por ende, más allá de entrar a afirmar que Disney promueve actitudes consumistas, los padres apuntan con mayor certeza a decir que los niños desarrollan competencias lúdicas, y de paso adquieren conciencia social al tener la posibilidad de ser artífices de procesos de participación dentro y fuera de la plataforma.

Sumado a esto, la percepción positiva hacia el Club Penguin y sus pilares Disney, hace que familias enteras asuman como contenidos apropiados casi cualquier cosa que se les presente y venga contramarcado o respaldado por el emporio Disney. De igual forma, los niños consideran que ellos son los artífices de sus ambientes en el mundo virtual, pudiendo ser un vigilante activo dentro de la plataforma para denunciar intentos de violaciones a la intimidad, $\mathrm{u}$ oficiar como un guía para usuarios nuevos que se sientan neófitos en el mundo virtual. Las posibilidades son amplias, y en la medida que los usuarios piensan en comunidad la plataforma se potencia día a día, siempre teniendo en cuenta que el Club Penguin pone las pautas de lo que se puede y no se puede hacer.

Club Penguin como cabeza visible de las MMO para niños, ha logrado en menos de una década consolidarse como un territorio ampliamente positivo, promoviendo en la infancia nuevos modos de construir realidad y de propiciar espacios lúdicos, de entretenimiento y de interacción; logrando poner una barrera de "hielo" suficientemente gruesa para blindarse de los peligros que en otros espacios porta Internet.

No obstante, no puede pasarse por alto que ese espacio a primera vista inocente es el mismo que se pone como el estandarte virtual de la habilidad "disneysiana", aquella capaz de transformar hasta la isla más fría en un sitio cálido para articular un emporio económico, que refuerza con plataformas de este tipo su posicionamiento global como una marca que se ha insertado culturalmente en las familias de todos los niveles sociales, trasmitiendo valores e intangibles que justifican su inconmensurable lucro económico.

\section{Referencias}

Adorno, T., y Morín, E. (1967). La industria cultural. Buenos Aires, Argentina: Galerna.

Ariès, P. (1962). Centuries of childhood: A Social History of Family Life. New York, USA: Vintage Books. 
Barnes, B. (2 de agosto de 2007). Disney Acquires Web Site for Children. The New York Times. Disponible en http://andromeda.rutgers.edu/ aristim/convergence2007/DisWeb4Children.pdf

Belli, S., y López, C. (2008). Breve historia de los videojuegos. Athenea Digital, (14). ISSN 15788946. Universidad Autónoma de Barcelona. Disponible en http://psicologiasocial.uab.es/athenea/index.php/atheneaDigital/article/ viewDownloadInterstitial/570/437

Berger, P. y Luckmann T. (1966). La construcción social de la realidad. Buenos Aires, Argentina: Amorrortu Editores.

Blumer, H. (1969). El Interaccionismo Simbólico: Perspectiva y método. Barcelona, España: Editorial Hora.

Buenaventura, D. (1998). Historia de la infancia. Barcelona, España: Editorial Ariel. 1aㅡ edición enero de 1998.

Deutscher, I. (1973). What we say/what we do: Sentiments $\mathcal{E}$ acts.

Dorfman, A., y Mattelart, A. (1973). Para leer al Pato Donald: comunicación de masas y colonialismo. Buenos Aires, Argentina: Siglo XXI editores.

Freud, S. (1921). Psicología de las masas y análisis del yo. Traducción de José L. Etcheverry. Amorrortu Editores, 18. Buenos Aires, Argentina.

Giroux, H. (2001). El ratoncito feroz: Disney o el fin de la inocencia. Traducción de Alberto Jiménez. Fundación Germán Sánchez Ruipérez. Madrid, España.

Jiménez, P., García S., y Maroto, E. (mayo de 1999). Tradición oral y cuentos, influencia anglo-germana. España: Facultad Ciencias de la Educación. Universidad de Málaga.

Montessori, M. (1936). El niño el secreto de la infancia. México: Editorial Diana.

Shaw, C. (1931). The natural history of a delinquent career. Chicago: The University of Chicago Press.

Steinkuehler, C. (2005). The New Third Place: Massively Multiplayer Online Gaming in American Youth Culture. Journal of Research in Teacher Education, (3), 16. Disponible en http://130.239.57.135/presentation/publikationer/lof/ lofu_nr3_2005.pdf\#page=16

Taylor, S., y Bogdan, R. (1987). Introducción a los métodos cualitativos de investigación: La búsqueda de significados. Barcelona: Editorial Paidós.

Watts, S. (1997). The Magic Kingdom, Walt Disney and the American way of life. New York, USA: Houghton Mifflin Company. 